\title{
A Study on the Impact the Shanghai-Hong Kong Stock Connect Making on the Long-Term Memory of Chinese Stock Market
}

\author{
Yongyue Zhang \\ School of Economics, Jinan University, Guangzhou, China \\ Email: zhangyongyue2@163.com
}

How to cite this paper: Zhang, Y.Y. (2017) A Study on the Impact the Shanghai-Hong Kong Stock Connect Making on the LongTerm Memory of Chinese Stock Market. Open Journal of Social Sciences, 5, 90-97. https://doi.org/10.4236/jss.2017.54009

Received: March 6, 2017

Accepted: April 18, 2017

Published: April 21, 2017

Copyright $\odot 2017$ by author and Scientific Research Publishing Inc. This work is licensed under the Creative Commons Attribution International License (CC BY 4.0).

http://creativecommons.org/licenses/by/4.0/

\begin{abstract}
Based on the log return of Shanghai composite index, this paper constructs Hurst index by $\mathrm{R} / \mathrm{S}$ analysis method to measure the long memory in stock market. The results show that there is strong long memory in China's stock market. After the opening of Shanghai-Hong Kong stock connection, the long memory in China's stock market has been reduced, so does the memory cycle. It means that the Shanghai-Hong Kong stock connection has a positive effect on enhancing the effectiveness of China's stock market.
\end{abstract}

\section{Keywords}

Shanghai-Hong Kong Stock Connect, Hurst Index, Long Memory

\section{Introduction}

In the early 1990s, the Shanghai stock exchange and Shenzhen stock exchange set up one after another, which marks the birth of the national stock market in China. After more than 20 years of development, the Initial Public Offerings (IPO) system and supervision system have been reformed for many years, at the same time, the reform of the shareholder structure in listed companies was basically completed, China's stock market is in the process of continuous improvement, but it is not completely integrate with the international market. On April 10th, 2014, Hong Kong's securities and futures commission and the China securities regulatory commission jointly issued a notice which include the approval of the Shanghai stock exchange and the Hong Kong stock exchange to carry out the interconnection mechanism of Shanghai-Hong Kong stock connect market trading, and allow investors in Shanghai and Hong Kong stock market to buy and sell Hong Kong stocks and A-shares through their local stock exchanges, 
then Shanghai-Hong Kong stock connect officially opened on November 17, 2014. With the gradual improvement of the interconnectivity in Shanghai and Hong Kong stock market, it marks that China's capital market opening to the outside world has an important step.

On August 16, 2016, the premier Li Keqiang made it clear that the related preparation work of the Shenzhen-Hong Kong stock connect almost had been ready on the executive meeting of the state council, and the state council has approved the deep port general plan. On October 11, 2016, the Hong Kong stock connection exchange, a wholly-owned subsidiary of the Hong Kong stock exchange, and the settlement of Hong Kong and the Shenzhen stock exchanges and China Securities Depository and Clearing Corporation Limited signed a quartet agreement about the Shenzhen-Hong Kong stock connect, which means that the open of Shenzhen-Hong Kong stock connect has entered the countdown.

Based on the deep port open event, using Rescaled Range Analysis (R/S) method to test the change of the Chinese stock market's long-term memory, to analyze the impact of Shanghai-Hong Kong stock connect and Shenzhen-Hong Kong stock connect which is about to open on the effectiveness of the Chinese stock market. This paper is organized in the following manner. In Section 2, the literature review, the main research results domestic and foreign scholars researched on the long memory of stock market are described. In Section 3, the empirical analysis and the main empirical results are presented. Section 4 is devoted to summarize the conclusions and the implications of the paper.

\section{Literature Review}

The existence of the stock market's long-term memory means the predictability of the market, which also means that the market is not effective. Hurst (1951) [1] found the long-term memory of hydrological time series through tidal data for the first time, then this kind of analysis method is widely used in fluid gradually learn, meteorology and geophysics, and other areas of the natural science and financial fields. Lo (1991) [2] applied the method to long-term memory effect analysis in the stock market for the first time. By adopting the modified R/S analysis method, the study showed that the American stock index returns distribution didn't exist in the long-term memory effect. Then Crato (1994) [3], Cheung \& Lai (1995) [4] and other scholars also confirmed the conclusion of Lo. However, Sourial (2002) [5] found that the week yield rate sequence of IFCGlobal index also exist long-term memory characteristics, in which Egypt Autoregressive Fractionally Integrated Moving Average (ARFIMA) and Fractionally Integrated Generalized Autoregressive Conditional Heteroskedasticity (FIGAR$\mathrm{CH})$ model was adopted.

Chen Menggen (2003) [6] adopted the modified R/S and ARFIMA to examine Chinese stock index and the sampled stocks, and they didn't think the stock index had long-term memory effect, and only a handful of shares the sequence of yield rate of the long memory effect existed. Geng Kehong and Zhang Shiying (2008) [7] proposed the long memory stochastic conditional duration model, 
and used spectrum likelihood function of genetic algorithm based on chaotic taboos model to analyze Shanghai Pudong development bank's share price, which showed that the long memory characteristics existed. Liu Rongmao and Liu Hengxin (2015) [8] who used R/S analysis and combined it with the Detrended Fluctuation Analysis (DFA) statistics concluded: Shanghai stock markets existed obviously long-term memory, but after Shanghai-Hong Kong stock connect, the long-term and short-term memory declined significantly.

\section{The Empirical Analysis}

\subsection{Data Selection and Pretreatment}

This article selects 1500 trading days' data of the Shanghai composite index from the July 20, 2010 to September19, 2016 as sample data. April 10, 2014 as the node, the period is divided into two stages, the stage of before the opening of Shanghai-Hong Kong stock connect is from July 20, 2010 to April 9, 2014, a total of 900 trading days' data, the other stage of after the opening of Shanghai-Hong Kong stock connect is from April 10, 2014 open on September 19, 2016, a total of 600 trading days' data.

For the convenience of analysis, in this paper, the Shanghai Composite Index is processed as follows, so that this paper gets the logarithm yield rate of Shanghai Composite Index.

$$
R_{t}=\log \frac{P_{t}}{P_{t-1}}
$$

In the equation above, $P_{t}$ represents the closing price of the Shanghai Composite Index at time $t, R_{t}$ represents the logarithm yield rate of Shanghai Composite Index at time $t$.

\subsection{Descriptive Statistics}

To draw the sequence of yield rate of the after pretreatment, as shown in Figure 1 , it can be seen that the yield rate fluctuates near zero and the fluctuation is concentrated. In addition, the histogram of Shanghai Composite Index's yield rate which is shown in Figure 2 shows that the characteristics of the return order of stock index is obvious peak and negative bias. At the same time, if the variable obeys normal distribution, and then the skewness should be 0 , the kurtosis should be 3 and the Jarque-Bera (JB) statistics should be 0 . However, the skewness of the yield rate sequence of Shanghai composite index is 0.9655 , kurtosis is 8.5105 and JB statistics is 2130.86 , it further suggests that the yield rate sequence doesn't accord with normal distribution. The characteristics of non-normality of yield rate sequence means that the yield rate of each point is not independent, but related. That is, yield rate has memory; the moment's change will affect the change of later time's yield rate.

\subsection{Unit Root Test}

Before using R/S analysis method, making unit root test to yield rate of the 


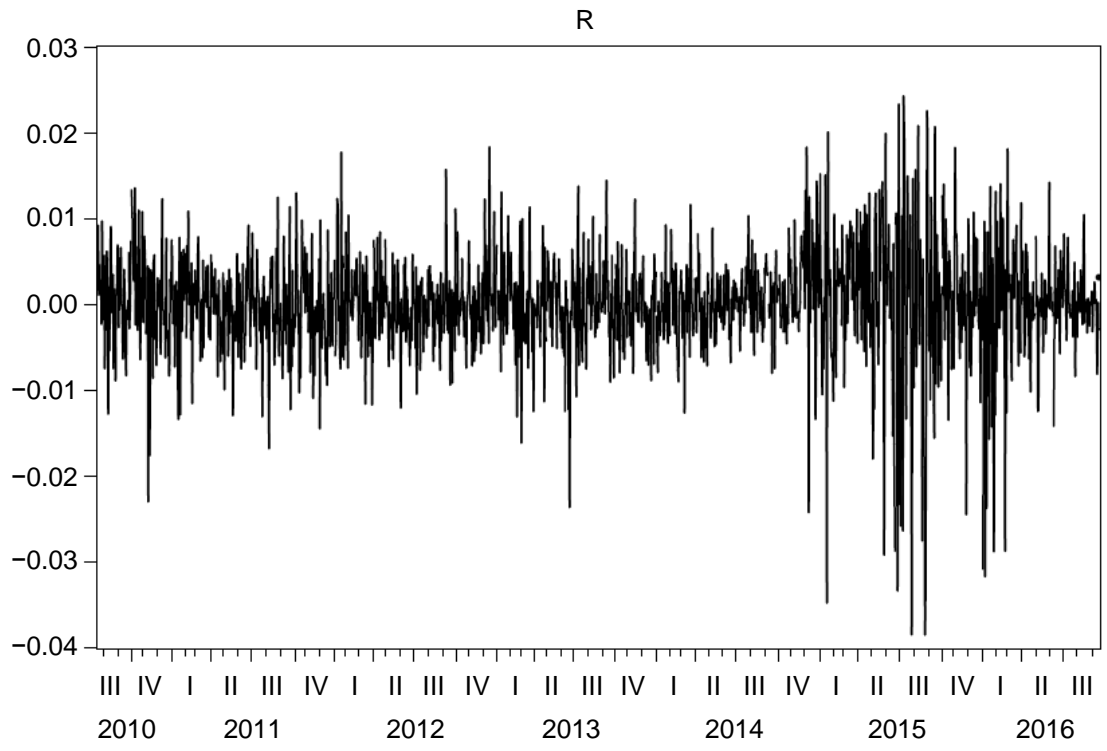

Figure 1. The sequence diagram of logarithm yield rate of the Shanghai composite index.

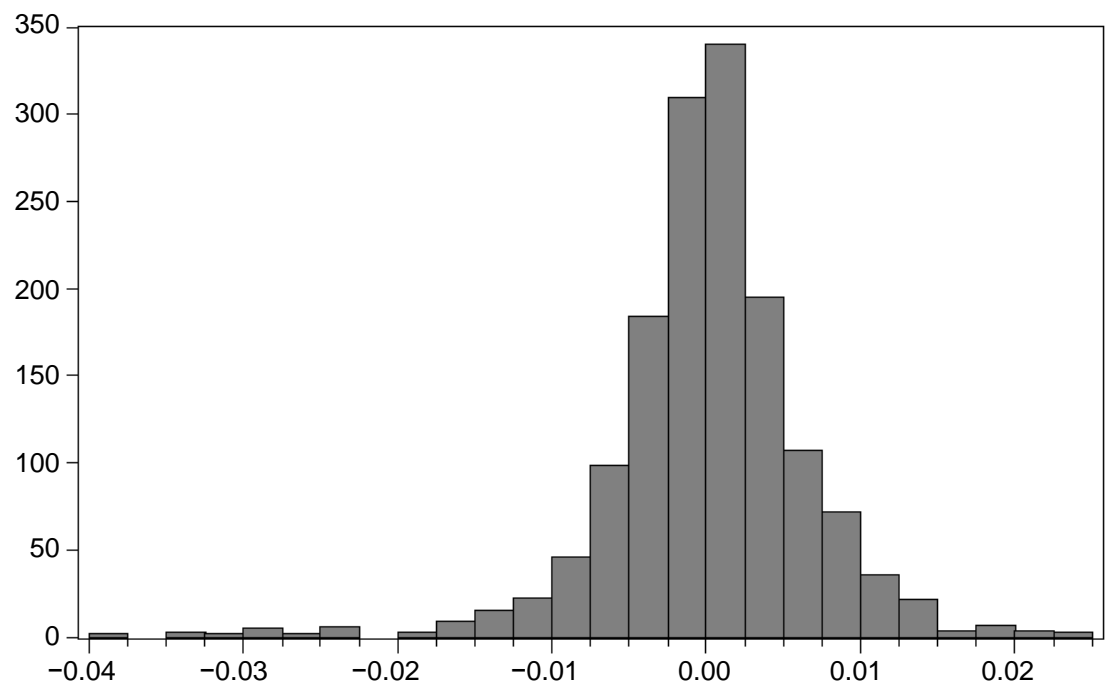

Figure 2. The histogram of logarithm yield rate of the Shanghai composite index.

Shanghai Composite index of the two stages before and after the opening of Shanghai-Hong Kong stock connection. Results presented in Table 1 show that the Augmented Dickey-Fuller (ADF) and the Phillips-Perron (PP) index refused the null hypothesis H0: sequence has a unit root, under the $1 \%$ significant level. However, the Kwiatkowski-Phillips-Schmidt-Shin (KPSS) indicator unable to reject its null hypothesis H0: sequence has a unit root, under the $10 \%$ significant level. The results above show that the yield rate of the Shanghai Composite index of the two stages before and after the opening of Shanghai-Hong Kong stock connection is stable.

\subsection{R/S Analysis Test}

\subsubsection{The Model Definition}

The Logarithm yield rate sequence of Shanghai Composite index $\left\{R_{t}\right\}$, this paper 
Table 1. The unit root test of yield rate sequence of the Shanghai composite index of the two stages before and after the opening of Shanghai-Hong Kong stock connect.

\begin{tabular}{cccc}
\hline & ADF & PP & KPSS \\
\hline Before the opening & $-29.8408^{* * *}$ & $-29.8407^{* * *}$ & 0.071554 \\
After the opening & $-22.7491^{* * *}$ & $-22.7453^{* * *}$ & 0.091551 \\
\hline
\end{tabular}

Note: ${ }^{*}{ }^{* *},{ }^{* * *}$, respectively show to reject the null hypothesis under $10 \%, 5 \%, 1 \%$ significant level.

makes a regression analysis under the situation of $R_{t}$ as dependent variable and $R_{t-1}$ as the independent variable, and then getting the residual sequence $\left\{X_{t}\right\}$ of the (Autoregressive) AR (1) model of $R_{t}$ Divide $\left\{X_{t}\right\}$ into A subsequences whose length is $n$, where $n \geq 3$. For each subsequence, the definition of range is as follows:

$$
R_{t}=\max \sum_{k=1}^{t}\left(X_{k}-\bar{X}_{n}\right)-\min \sum_{k=1}^{t}\left(X_{k}-\bar{X}_{n}\right), t=1,2,3, \cdots, n
$$

Set $S_{t}$ as a standard deviation of the subsequence, then the $R / S$ of a subsequence whose length is $A$ is defined as follows:

$$
(R / S)_{n}=\frac{1}{A} \sum_{k=1}^{A} \frac{R_{k}}{S_{k}}
$$

Then the Hurst index $H$ can be calculated as follows:

$$
K n^{H}=(R / S)_{n}
$$

After the logarithm based on the Equation (4), and then making Ordinary Least Squares (OLS) regression, the slope of regression equation is the estimate value of Hurst index $H$.

In order to determine the memory cycle of the sequence, define $V_{n}$ statistics as follows:

$$
V_{n}=(R / S)_{n} / \sqrt{n}
$$

when $0.5<H<1$, the sequence is a long-term memory, $V_{n}$ tilts upward about $\log (n)$; When $H=0.5$, the sequence is an independent random process, $V_{n}$ is horizontal about $\log (n)$; When $0<H<0.5$, the performance of the sequence is anti-persistence, $V_{n}$ tilts downward about $\log (n)$. Therefore, when the morphological of $V_{n}$ about $\log (n)$ changes, then memory cycle ends and long-term memory disappears.

\subsubsection{The Empirical Results}

Segment the yield rate sequence of the Shanghai Composite index in the stage of before the opening of Shanghai-Hong Kong stock connect which includes 900 trading days and the stage of after the opening which includes 600 trading days, at the same time, calculate the relevant index of each subsequence, which is shown in the following Table 2.

Make a graph according to $V_{n}$ and $\log (n)$, as shown in Figure 3, the figure indicates that $V_{n}$ declines significantly, when $n=150$, before the opening of Shanghai-Hong Kong stock connect, which means that before the opening of 
Table 2. The summary tables of each subsequence's related indicators before and after the opening of Shanghai-Hong Kong stock connect.

\begin{tabular}{|c|c|c|c|c|c|}
\hline \multicolumn{3}{|c|}{ Before the opening } & \multicolumn{3}{|c|}{ After the opening } \\
\hline$n$ & $(R / S)_{n}$ & $V_{n}$ & $n$ & $(R / S)_{n}$ & $V_{n}$ \\
\hline 450 & 25.0820 & 1.1824 & 300 & 20.2374 & 1.1684 \\
\hline 300 & 19.3770 & 1.1187 & 200 & 19.2153 & 1.3587 \\
\hline 225 & 18.2278 & 1.2152 & 150 & 12.6057 & 1.0292 \\
\hline 180 & 14.5659 & 1.0857 & 120 & 12.2280 & 1.1163 \\
\hline 150 & 13.7442 & 1.1222 & 100 & 10.8047 & 1.0805 \\
\hline 100 & 11.4431 & 1.1443 & 75 & 9.0145 & 1.0409 \\
\hline 90 & 10.2553 & 1.0810 & 60 & 7.9608 & 1.0277 \\
\hline 75 & 9.5861 & 1.1069 & 50 & 7.1806 & 1.0155 \\
\hline 60 & 8.6374 & 1.1151 & 40 & 6.5442 & 1.0347 \\
\hline 50 & 7.8138 & 1.1050 & 30 & 5.5302 & 1.0097 \\
\hline 45 & 6.8808 & 1.0257 & 25 & 5.0747 & 1.0149 \\
\hline 36 & 6.2012 & 1.0335 & 24 & 4.9823 & 1.0170 \\
\hline 30 & 5.5354 & 1.0106 & 20 & 4.5581 & 1.0192 \\
\hline 25 & 4.7816 & 0.9563 & 15 & 3.7010 & 0.9556 \\
\hline 20 & 4.3109 & 0.9639 & 12 & 3.1186 & 0.9003 \\
\hline 18 & 3.9980 & 0.9423 & 10 & 2.8305 & 0.8951 \\
\hline 15 & 3.6387 & 0.9395 & 8 & 2.3971 & 0.8475 \\
\hline 12 & 3.0849 & 0.8905 & 6 & 1.9615 & 0.8008 \\
\hline 10 & 2.7786 & 0.8787 & 5 & 1.7443 & 0.7801 \\
\hline 9 & 2.5951 & 0.8650 & 4 & 1.4247 & 0.7123 \\
\hline 6 & 1.9615 & 0.8008 & 3 & 1.1046 & 0.6377 \\
\hline 5 & 1.7086 & 0.7641 & & & \\
\hline 4 & 1.4301 & 0.7150 & & & \\
\hline 3 & 1.1022 & 0.6364 & & & \\
\hline
\end{tabular}

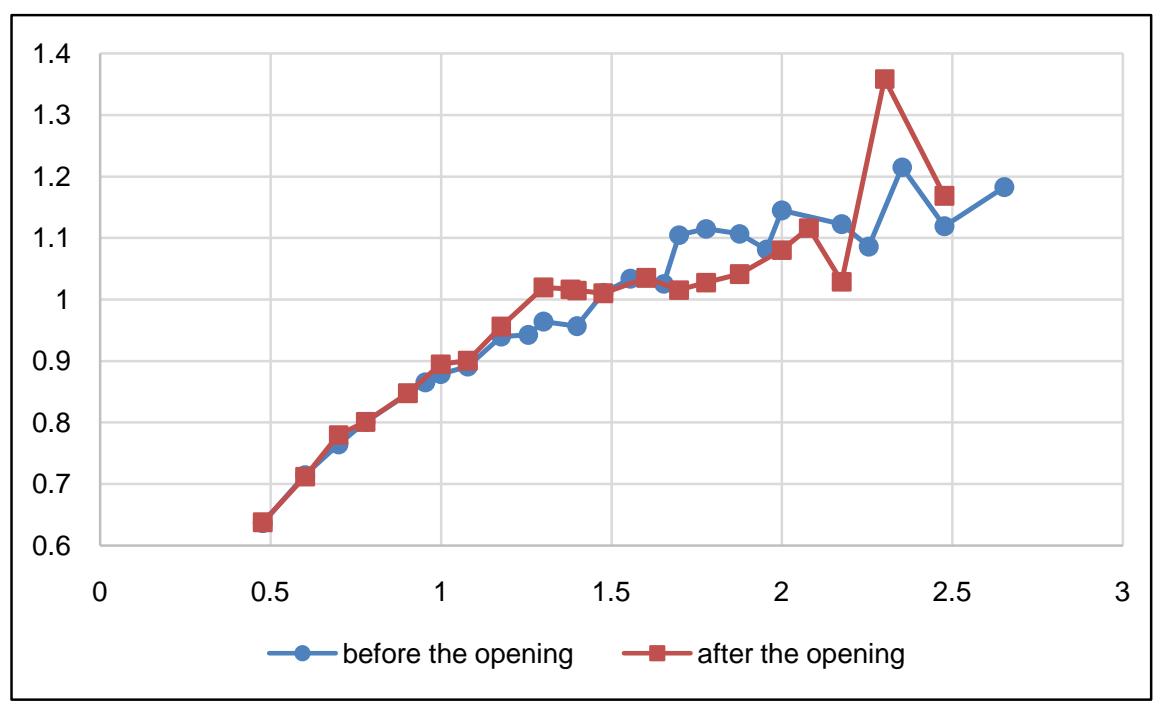

Figure 3. The $V_{n}$ statistics of residual sequence before and after the opening of Shanghai-Hong Kong stock connect. 
Shanghai-Hong Kong stock connection, long-term memory cycle is 150 days. Similarly, after the opening of Shanghai-Hong Kong stock connection, long-term memory cycle is 120 days, and memory cycle decreased in some extent.

According to the different memory cycle and relevant indicators before and after the opening of Shanghai-Hong Kong stock connect, make OLS regression estimation for the yield rate residual sequence, the results as shown in Table 3, it can be seen that Hurst indexes are more than 0.5 both before and after the opening, which proves the existence of long-term memory. However, after the opening of Shanghai-Hong Kong stock connection, Hurst index has narrowed, which shows that the long-term memory of the sequence has dropped.

\section{Conclusions and Implications}

In this paper, we use the $\mathrm{R} / \mathrm{S}$ analysis method to construct the Hurst index to measure the degree of strength of long-term memory. The study finds that the Hurst index of China's stock market was more than 0.6, indicating that there existed a strong long-term memory in the market. After the opening of ShanghaiHong Kong stock connection, the Hurst index decreased from 0.6369 to 0.6272 , even though the Hurst index decreased with a small range. The result revealed that the long-term memory of China's stock market declined to some extent. At the same time, before the opening of Shanghai-Hong Kong stock connection, the long-term memory cycle was 150 days, and the long-term memory cycle was shortened to 120 days by the opening. This evidence further confirms the decline in long-term memory. This reduction in long-term memory shows that the opening of Shanghai-Hong Kong stock connection has a positive effect on improving the effectiveness of China's stock market.

Combined with the empirical results, this paper has the following three aspects of the revelation.

Firstly, China's stock market still has strong long-term memory to some extent, which discovers that there still exist many shortcomings and particularity in China's stock market, Examples are as follows, the stock market is short of the instrument of avoiding risk, the information disclosure system is imperfect and the trading action of investors in China's stock market often tend to the same direction, producing agglomeration effect. As a result, the Government of China needs to improve and innovate the regulatory system; in addition, to strengthen the education of investors is also important.

Secondly, although the opening of Shanghai-Hong Kong stock connect reduced the long-term memory of China's stock market, the degree of reduction is low. This result above is related to the restrictions of Shanghai-Hong Kong stock

Table 3. The regression results of the residual sequence before and after the opening of Shanghai-Hong Kong stock connect.

\begin{tabular}{cccccc}
\hline $\mathrm{N}$ & intercept & Hurst index & $C_{t}$ & $R^{2}$ & $F$ \\
\hline Before the opening $(3 \leq n \leq 150)$ & -0.2093 & 0.6369 & 0.2090 & 0.9960 & 4496.93 \\
After the opening $(3 \leq n \leq 120)$ & -0.1965 & 0.6272 & 0.1928 & 0.9931 & 2315.35 \\
\hline
\end{tabular}


connect itself, for example, the investment threshold of Shanghai-Hong Kong stock connect is higher than A-share stock market for both domestic investors and Hong Kong stock market's investors, and not only that, the degree of openness of the market is not high, in addition, the trading mechanism of two stock markets is different and so on. In order to reduce the long-term memory of China's stock market and further promote the healthy and sustainable development of China's stock market, Chinese government should gradually release these restrictions in the process of developing the Shanghai-Hong Kong stock connection.

In the end, referring to the analysis of this paper, the opening of ShenzhenHong Kong stock connection will have a significant impact on the long-term memory of China's stock market. Compare to the Shanghai-Hong Kong stock connect, the pressure of the opening of Shenzhen-Hong Kong stock connection is increased, along with the opening enlargement, the impact which China's stock market can feel will be further expanded.

\section{References}

[1] Hurst, H.E. (1951) Long Term Storage Capacity of Reservoirs. Transactions of the American Society of Civil Engineers, 116, 776-808.

[2] Lo, A.W. (1991) Long-Term Memory in Stock Market Prices. Econometrica, 59, 1279-1313. https://doi.org/10.2307/2938368

[3] Crato, N. (1994) Some International Evidence Regarding the Stochastic Memory of Stock Returns. Applied Financial Economics, 4, 33-39. https://doi.org/10.1080/758522123

[4] Cheung, Y.W. and Lai, K.S. (1995) A Search for Long Memory in International Stock Market Returns. Journal of International Money \& Finance, 14, 597-615. https://doi.org/10.1016/0261-5606(95)93616-U

[5] Sourial, M.S. and Sourial, M.S. (2002) Long Memory Process in the Egyptian Stock Market. SSRN Electronic Journal. https://doi.org/10.2139/ssrn.297220

[6] Cheng, M.G. (2003) An Empirical Study on Long-Term Memory of Chinese Stock Market. Journal of Economic Research, No. 3, 70-78. (In Chinese)

[7] Zhang, S.Y. and Geng, K.H. (2007) A Study on Long Memory of Ultra-High Frequency Duration Sequence of China's Stock Market. Journal of Jiangxi University of Finance, 16, 103-107. (In Chinese)

[8] Liu, R.M. and Liu, H.X. (2015) The Impact of Shanghai-Hong Kong Stock Connect on the Effectiveness of Stock Market. Journal of Economic and Management Research, No. 8, 54-62. (In Chinese) 
Submit or recommend next manuscript to SCIRP and we will provide best service for you:

Accepting pre-submission inquiries through Email, Facebook, LinkedIn, Twitter, etc. A wide selection of journals (inclusive of 9 subjects, more than 200 journals)

Providing 24-hour high-quality service

User-friendly online submission system

Fair and swift peer-review system

Efficient typesetting and proofreading procedure

Display of the result of downloads and visits, as well as the number of cited articles Maximum dissemination of your research work

Submit your manuscript at: http://papersubmission.scirp.org/

Or contact jss@scirp.org 